\title{
INTERACTION BETWEEN OLEATE AND THE LIPOPROTEINS OF HUMAN SERUM
}

\author{
BY ROBERT S. GORDON, JR. \\ (From the Laboratory of Metabolism, National Heart Institute, National Institutes of Health, \\ Public Health Service, Department of Health, Education, and Welfare, Bethesda, Md.)
}

(Submitted for publication July 16, 1954; accepted October 27, 1954)

Since the pioneer observations of Hahn (1), who noted that heparin injection caused the disappearance of visible lipemia, and of Anderson and Fawcett (2), who showed that this effect was due not to heparin itself but to a "clearing factor" which appeared in plasma after heparin injection, there has been considerable interest in the biochemical and physiological aspects of this phenomenon, often called the "clearing reaction." A variety of effects over and above the mere disappearance of turbidity has been attributed to clearing factor action. Evidence presented by several independent groups of investigators (3-7) would appear to establish the fact that in the presence of clearing factor, triglycerides are hydrolyzed in in vitro systems with the liberation of glycerol and free fatty acids. This conclusion is further confirmed by a considerable amount of data from this laboratory which are, as yet, unpublished (8). The lipolytic reaction may be broadly formulated as follows:

$$
\begin{gathered}
\text { Triglyceride } \\
\text { substrate }
\end{gathered}+\begin{gathered}
\text { Fatty acid } \\
\text { acceptor }
\end{gathered}
$$$$
\underset{\text { other activating }}{\stackrel{\text { Clearing factor }}{\longrightarrow}}
$$
factors

\section{Glycerol + Acceptor - Fatty acid complex.}

The triglyceride substrate may consist of chylomicra, artificial oil emulsions, or lipoprotein material. Serum albumin and calcium ions have been shown to serve as fatty acid acceptors. There is no evidence that clearing factor is consumed in the reaction, and in other respects it appears to function in an enzymatic role. The presence of other activating factors for the reaction is suspected $(5,6)$, but such substances have as yet not been isolated, and their functions are unknown.

In addition, other less well understood effects of clearing factor have been described. Boyle, Bragdon, and Brown (9), and Lindgren, Freeman, and Graham (10) have noted changes in ultracentrifugal lipoprotein patterns following the action of clearing factor. The effects of heparin on the electrophoretic distribution of plasma proteins have been studied recently by a number of authors. Using the moving boundary technique, Nikkilä (11) and Lever, Smith, and Hurley $(12,13)$ noted that the administration of heparin to a lipemic individual resulted in a decrease of the quantity beta globulin and a compensatory increase in the amount of alpha globulin or albumin, or, in some of the patients studied by Lever, Smith, and Hurley, the formation of a new pre-albumin component. These phenomena were attributed by the latter authors to an increase in the mobility of beta lipoprotein which caused it to appear in an abnormal position in the electrophoretic pattern. With techniques of zone electrophoresis in starch and filter paper media, Nikkilä (14), Rosenberg (15), Comfort (16), Herbst and Hurley (17), and Bolinger, Grady, and Slinker (18) have shown that the administration of heparin in the presence of lipemia causes the lipid-containing plasma proteins to migrate more rapidly. There is general agreement among the authors cited that heparin injection and lipemia are both prerequisite to the production of the electrophoretic effects; administration of heparin to fasting normal subjects was generally found to produce little or no alteration in the electrophoretic patterns.

Lever, Smith, and Hurley (12) advanced the hypothesis that these electrophoretic changes might be due to loss of lipid from lipoproteins, resulting in a decrease in molecular size. The possibility that they were due to combination of heparin with lipoproteins was also considered. One other hypothetical explanation remained untested, namely that the fatty acids evolved in the clearing reaction might be influencing the electrophoretic results. Armstrong, Budka, and Morrison (19) had indeed already obtained electrophoretic patterns not unlike those of Lever, Smith, 
and Hurley by examining whole plasma in a medium containing $0.05 \mathrm{M}$ sodium caprylate. It therefore appeared desirable to investigate the effect of higher fatty acids, such as might be evolved from hydrolysis of blood lipids, on the electrophoretic behavior of plasma proteins. For the present investigation, oleate was chosen as a representative higher fatty acid anion because of its relative abundance in food fats, its easy availability in relatively pure form, and its easy solubility.

\section{MATERIALS AND METHODS}

The blood samples used were obtained from patients on the Heart Institute Service at the Clinical Center of the National Institutes of Health. Venipuncture was carried out with minimal venous stasis, and blood coagulation prevented by the addition of solid disodium ethylene diaminetetraacetic acid. The samples were cooled as quickly as possible in thin-walled test tubes immersed in ice water, and the plasma separated by centrifugation in the cold. As soon as possible, an equal volume of $2 \mathrm{M}$ sodium chloride solution was added to each plasma sample in order to produce irreversible inactivation of clearing factor. These precautions served to minimize, but probably not to eliminate completely, continuation of the clearing reaction in vitro after the blood was withdrawn $(4,11,20)$. A standard intravenous dose of $0.75 \mathrm{mg}$. per Kg. (100 Toronto units per mg.) of commercial sodium heparinate was employed. Electrophoretic analyses were carried out in the Aminco portable apparatus which is equipped with a Philpott-Svensson-Thovaert cylindrical lens optical system. A phosphate buffer of $\mathrm{pH} 7.8$ and ionic strength 0.16 was employed; sera dialyzed against this buffer were analyzed at 2.7 -fold final dilution. The temperature of the bath (which was also used for conductivity measurements) was $1.2^{\circ} \mathrm{C}$. Paper electrophoresis was performed by the procedure of Swahn (21) with minor modifications. Standard sodium oleate solution was prepared by neutralizing a weighed quantity of commercial C.P. grade oleic acid. Armor bovine Fraction V (without added preservative) was used as a source of serum albumin, and the beta lipoprotein was prepared by Dr. Edwin Boyle of this laboratory by ultracentrifugal fractionation of pooled human serum obtained through the courtesy of the American National Red Cross. Ultracentrifugal analysis of this preparation revealed it to contain 99 per cent of a single $S_{f} 3-8$ component. Nitrogen was determined by the method of Markham (22), cholesterol by the modified SchoenheimerSperry method (23), lipid phosphorus by the procedure of Fiske and SubbaRow (24), and neutral fat by a modification of the method of Bragdon (25).1

\footnotetext{
1 The author expresses his gratitude to Drs. E. Middleton and J. Bragdon, National Heart Institute, for carrying out these analyses.
}

\section{EXPERIMENTAL RESULTS}

The findings of Lever, Smith, and Hurley (12, 13) were confirmed on a small group of patientsthree with essential hypercholesterolemia, one with idiopathic hyperlipemia, and two normal subjects with exogenous alimentary lipemia. The abnormal cases were fasting when studied. The clinical data regarding the four abnormal subjects are summarized in Table I. All received heparin intravenously and serial blood samples were taken during the course of the subsequent hour. The electrophoretic results obtained in patient M. M. are reproduced in Figure 1. Similar changes were seen in the other cases, but with differences in degree and in duration. In each patient the early post-heparin samples showed a diminution in the area of the beta 1 globulin peak, with increase in the area in the alpha globulin or albumin regions, and, in some instances, with appearance of a new component ahead of albumin. In later samples, these changes were reversed in

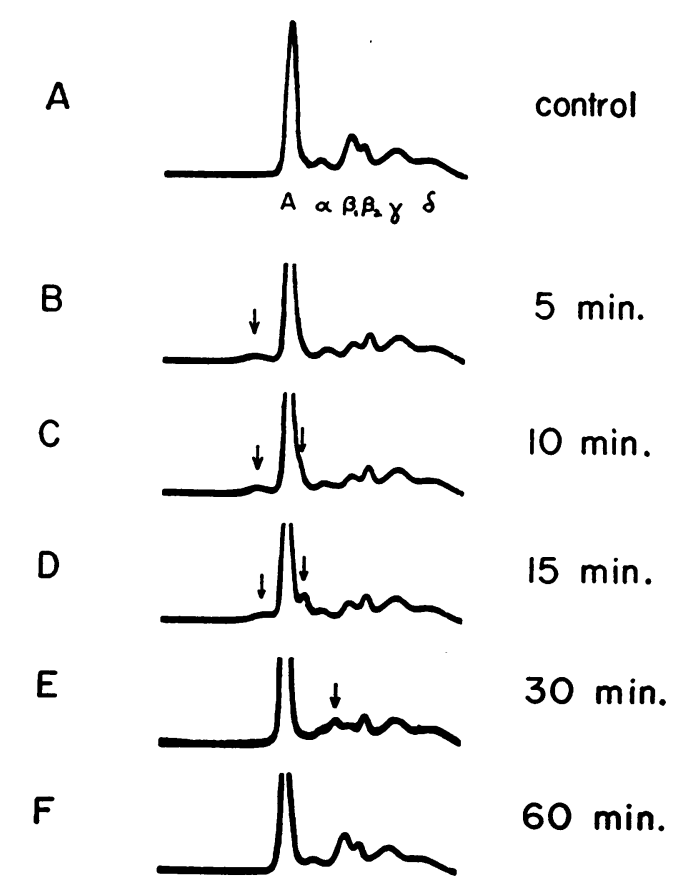

Fig. 1. In Vivo Effect of Heparin on Hypercholesterolemic Plasma (Patient M. M.)

Ascending limb electrophoretic patterns of control plasma (A) and samples taken 5, 10, 15, 30, and 60 minutes after heparin (B through $F$, respectively). The arrows indicate the components of changing mobility wherever they are resolved. 
A

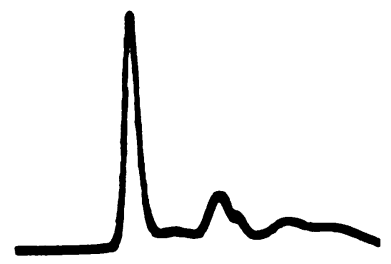

$A \alpha \beta_{1} \beta_{2} \gamma \delta$

B

C

Fig. 2. Effect of Incubating Hypercholesterolemic Plasma taken after Heparin Administration (Patient E. C.)

Ascending limb electrophoretic patterns of control plasma (A), post-heparin plasma chilled rapidly (B), and post-heparin plasma incubated (C). The arrows indicate the component whose mobility varies.

a gradual but orderly fashion. All the changes observed were compatible with the hypothesis that a beta ${ }_{1}$ globulin was temporarily acquiring a higher mobility so as to be superimposed on alpha globulin or albumin, and that an additional component, originally not resolved from albumin, was simultaneously increasing its mobility so as to precede albumin. These two components are best seen in Figure 1D which, when compared with $1 \mathrm{~A}$, shows two components previously absentone ahead of albumin and one migrating between albumin and alpha globulin, and a distinct decrease in the area of the beta ${ }_{1}$ globulin peak.

In order to examine the effect of continuation of the clearing reaction in vitro, a specimen collected from patient $\mathrm{E}$. C. five minutes after heparin administration was deliberately incubated for one hour at $37^{\circ} \mathrm{C}$. before being chilled; another aliquot of the same specimen was treated as described above. The results appear in Figure 2, where it is apparent that incubation in vitro increased the forward displacement of the beta globulin component. In this individual the effect of heparin was much less dramatic than that shown in Figure 1, and it is of interest that the component migrating ahead of albumin did not appear.

The possibility that heparin per se, rather than clearing factor, influences the electrophoretic pattern of plasma seemed unlikely in view of the small quantities used $(0.75 \mathrm{mg}$. per $\mathrm{Kg}$. is equivalent to approximately $15 \mu \mathrm{g}$. per ml. plasma). A sample of plasma treated with this quantity of heparin in vitro and analyzed electrophoretically showed no alteration when compared to an untreated control.

Addition of sodium oleate to plasma, on the other hand, produced striking changes. In Figure 3 are reproduced a series of analyses on the

A

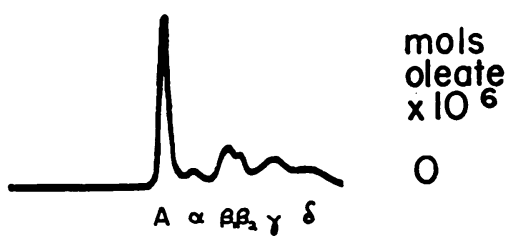

B

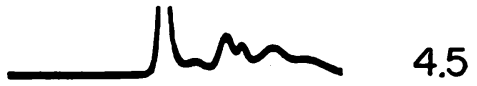

C

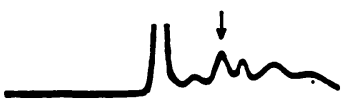

D

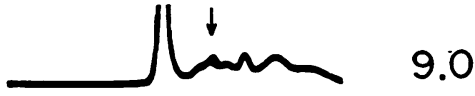

$E$

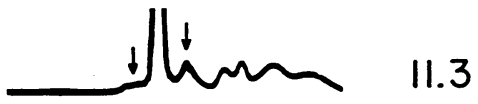

F

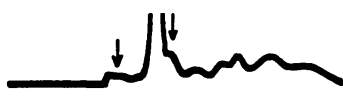

G

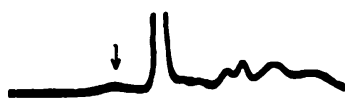

Fig. 3. In Vitro Effect of Oleate on Hypercholesterolemic Plasma (Patient M. M.)

Ascending limb electrophoretic patterns of $3 \mathrm{ml}$. plasma samples to which have been added $0,4.5,6.7$, 9.0, 11.3, 13.5, and $15.7 \times 10^{-6}$ moles of oleate (A through $G$, respectively). The arrows indicate the components of changing mobility wherever they are resolved. 


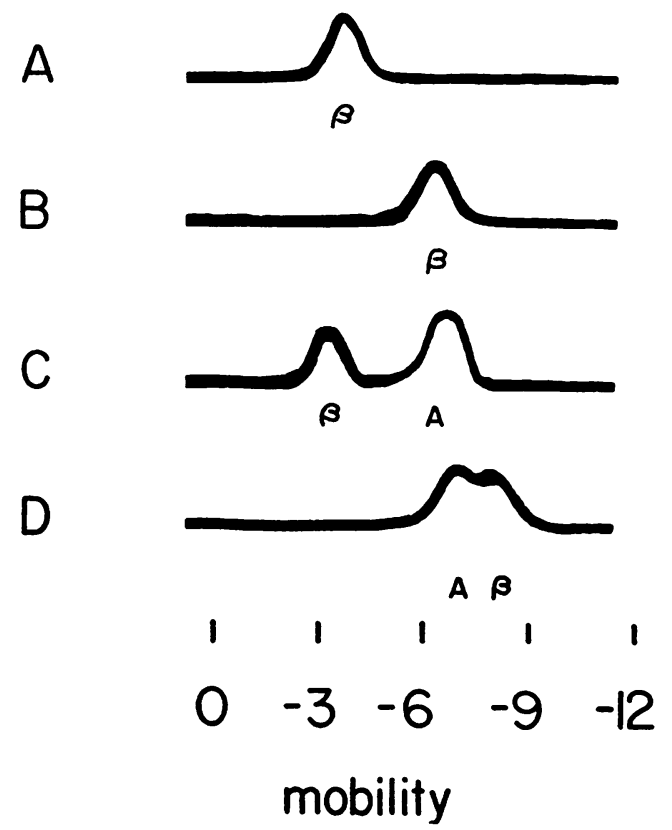

Fig. 4. Interactions of Isolated $\beta$-Lipoprotein, SErum Albumin, and Oleate (See Text)

Descending limb electrophoretic patterns, with abscissa showing mobility in $\mathrm{cm}^{2} / \mathrm{volt} \mathrm{sec} . \times 10^{5}$. The ordinates of the several patterns are only approximately comparable.

fasting plasma of patient M. M. With the addition of increasing amounts of sodium oleate a series of electrophoretic patterns is produced which resemble very closely those observed in post-heparin plasma.

In agreement with Lever, Smith, and Hurley $(12,13)$ it was surmised that the components being affected in these experiments were the lipo- proteins. Experiments were therefore designed to test this hypothesis. First, using hypercholesterolemic plasma treated in vitro with an excess of oleate, it was possible to isolate from the ascending limb of the electrophoretic cell enough of the material migrating ahead of albumin to permit simultaneous cholesterol and nitrogen analyses. The $0.5 \mathrm{ml}$. sample contained $0.34 \mathrm{mg}$. cholesterol and $0.054 \mathrm{mg}$. nitrogen, a cholesterol to nitrogen ratio of 6 to 1 , in fair agreement with the value given for beta lipoprotein by Oncley, Gurd, and Melin (26). Secondly, the use of paper electrophoresis with lipophilic staining made it possible to observe the effect of oleate added in vitro on the rate of movement of alpha and beta lipoproteins. Increasing amounts of oleate added to normal serum produced a gradual increase of mobility of each of these components without a significant change in their concentrations (we have not been able to reproduce the accurate quantitative results reported by Swahn). The maximal mobility increases observed amounted to 45 per cent and 65 per cent of the control mobilities for alpha and beta lipoproteins, respectively.

Since serum albumin is known to have a marked affinity for anions of the fatty acid series (27), experiments were undertaken to determine to what extent albumin could prevent or reverse the effects of oleate on lipoproteins. Figure 4 shows the interactions of oleate, albumin, and freshly isolated beta lipoprotein. An approximately 1 per cent solution of the beta lipoprotein alone gave the electrophoretic pattern shown in Figure 4A. Ad-

TABLE I

\begin{tabular}{|c|c|c|c|c|c|c|c|c|}
\hline Patient & Age & Sex & Primary diagnosis & $\begin{array}{c}\text { Secondary diagnoses and } \\
\text { complications }\end{array}$ & $\begin{array}{c}\text { Total } \\
\text { choles- } \\
\text { terol } \\
m g . \% \\
\end{array}$ & $\begin{array}{c}\text { Free } \\
\text { choles- } \\
\text { terol } \\
m g . \%\end{array}$ & $\begin{array}{c}\text { Phospho- } \\
\text { lipid } \\
\text { mg. \% }\end{array}$ & $\begin{array}{c}\text { Neutral } \\
\text { fat } \\
\text { mg. \% }\end{array}$ \\
\hline M. M. & 58 & $\mathbf{F}$ & $\begin{array}{l}\text { Hypercholesterolemia, } \\
\text { family history } \\
\text { unknown }\end{array}$ & $\begin{array}{l}\text { Xanthomatosis tuberosum } \\
\text { et tendinosum } 20 \mathrm{yr} \text {. } \\
\text { Mild diabetes } 2 \text { yr. }\end{array}$ & 377 & 89 & 414 & 410 \\
\hline E. C. & 44 & $\mathbf{M}$ & $\begin{array}{l}\text { Hypercholesterolemia, } \\
\text { familial trend } \\
\text { probable }\end{array}$ & $\begin{array}{l}\text { Xanthomatosis tendinosum } \\
30 \text { yr. Angina pectoris } \\
7 \text { yr. Myocardial } \\
\text { infarction } 3 \text { yr. ago }\end{array}$ & 382 & 92 & 354 & 240 \\
\hline J. K. & 58 & $\mathbf{M}$ & $\begin{array}{l}\text { Hypercholesterolemia, } \\
\text { family history } \\
\text { unknown }\end{array}$ & $\begin{array}{l}\text { Angina pectoris } 12 \text { yr. } \\
\text { Myocardial infarction } \\
12 \text { yr. ago }\end{array}$ & 334 & 71 & 286 & 210 \\
\hline L. S. & 41 & $\mathbf{M}$ & $\begin{array}{l}\text { Idiopathic } \\
\text { hyperlipemia }\end{array}$ & $\begin{array}{l}\text { Myocardial infarction } \\
2 \text { yr. ago }\end{array}$ & 379 & 139 & 496 & 1,100 \\
\hline
\end{tabular}


dition of oleate to a final concentration of $5.6 \times$ $10^{-4} \mathrm{M}$ nearly doubled its mobility, as shown in Figure 4B. To this mixture was then added onetenth its volume of a previously dialyzed 10 per cent bovine albumin solution. Repetition of the electrophoresis gave the result shown in Figure $4 \mathrm{C}$; the mobility of the lipoprotein returned to a value consistent with its mobility as seen in whole plasma. Further addition of oleate to a final concentration of $2.2 \times 10^{-3}$ again increased the mobility of the lipoprotein so that it exceeded that of albumin, as shown in Figure 4C. The albumin also showed a slight mobility increase with the increase in oleate concentration.

The partition of oleate between albumin and beta lipoprotein was further studied in a series of electrophoretic analyses performed on mixtures of oleate with fresh normal serum from a fasting subject. Patterns not unlike those shown in Figure 3 were obtained, and for each sample the mobilities of albumin and of the shifting beta peak were determined. Albumin mobility was measured in the descending limb; for the beta peak it was necessary to use the more clearly resolved pattern of the ascending limb. The albumin concentration of the serum was obtained from the same electrophoretic patterns, and in Figure 5 are plotted the mobilities as a function of the mole ratio of oleate to albumin in each sample. It is seen that the mobility of albumin increases in linear fashion with increasing mole ratio up to a mole ratio of 3 or 4 to one. Thereafter its mobility tends to become constant, whereas the mobility of the beta globulin component increases progressively.

\section{DISCUSSION}

The electrophoretic results here presented are best explained by postulating an interaction between oleate ions and alpha and beta lipoproteins. Association of oleate ions with the lipoproteins makes their net charge more negative and accelerates their anodic mobility. The reversibility of the association of oleate with beta lipoprotein is shown by the ability of albumin to restore normal mobility to a lipoprotein sample previously treated with oleate. When oleate is added to whole serum or plasma, competition between albu$\min$ and the lipoproteins for the oleate is to be expected. Some aspects of this competition can be deduced from the data of Figure 5. As increasing amounts of oleate are added to whole serum, the initial effect is on the albumin alone. Since oleate does not appear to penetrate the cellophane dialy-

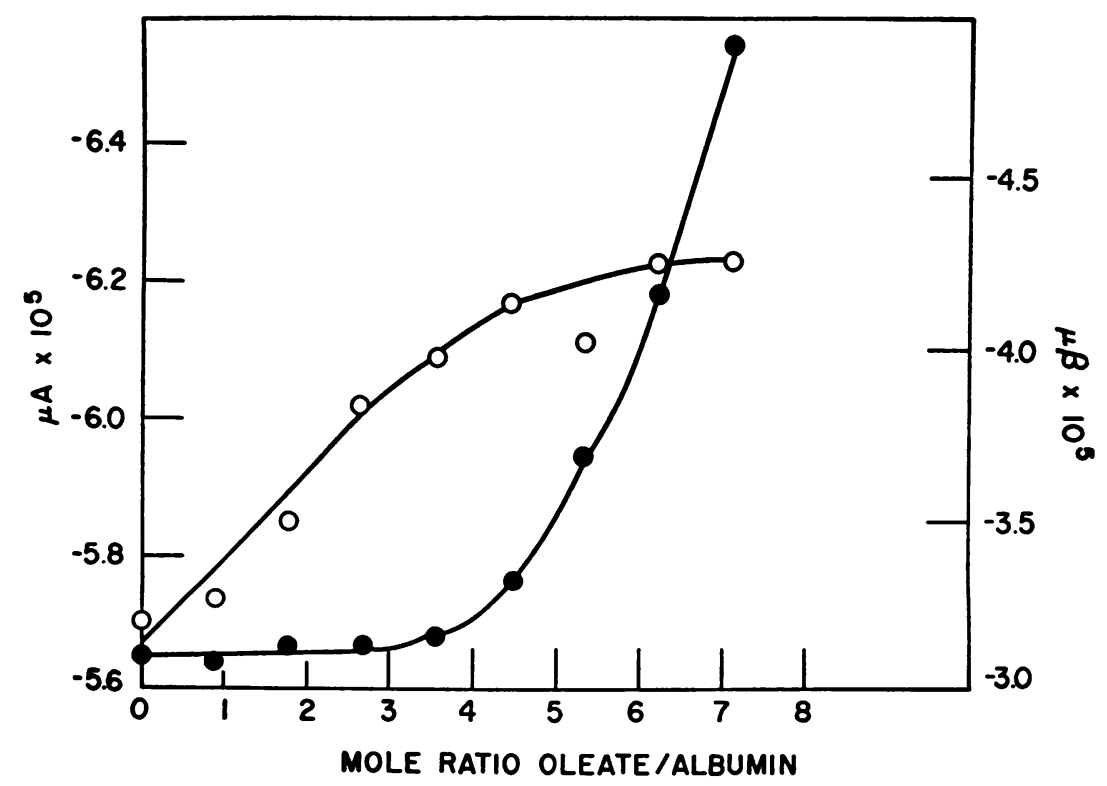

Fig. 5. Interactions of $\beta$-Lipoprotein, Serum Albumin, and Oleate in Whole Serum (See Text)

Open circles-mobility of albumin $\left(\mu_{\Lambda}\right)$. Solid circles-mobility of $\beta$ lipoprotein $\left(\mu_{\beta}\right)$. 
sis tubing used for these experiments (as evidenced by constancy of the surface tension of the dialysate), it must be assumed that up to a mole ratio of approximately 3 to 1 , added oleate is bound completely by albumin. It is of interest to compare this result with that obtained by Cogin (28) using bovine albumin-elaidic acid mixtures in a phosphate buffer of $\mathrm{pH} 6.8$. In her experiments the mobility of albumin continued to increase linearly until a mole ratio of 7 to 1 was reached, whereas here, when a mole ratio of 3 to 1 is exceeded, the albumin mobility ceases to increase linearly, and the mobility of beta lipoprotein is increased. From this point on, beta lipoprotein receives an ever increasing share of the added oleate, with the mobility of albumin tending to become constant. It would appear from the data presented in Figure 3 that alpha lipoprotein is least easily affected and binds oleate only after some of the latter has reacted with beta lipoprotein. However, the phosphate buffer used in this series of experiments, while permitting a better demonstration of the oleate-albumin interaction than does sodium diethylbarbiturate buffer, does not resolve alpha lipoprotein from albumin until the former has combined with enough oleate that its mobility is markedly increased. Small changes in the mobility of alpha lipoprotein occurring with lower concentrations of oleate in plasma might therefore have gone undetected.

In the light of these findings, the various results reported in the electrophoretic patterns of post-heparin plasmas may be assembled into a reasonable overall picture. In all cases in which heparin was given to a lipemic subject (either pathologic or alimentary lipemia) fatty acids were evolved which altered the mobilities of the lipoproteins. The extent of the mobility change will depend upon a number of variables which are not subject to easy control. The most significant is undoubtedly the concentration of available triglyceride substrate in the plasma of the subject under investigation. Thus the electrophoretic alteration is maximal in patients with essential hyperlipemia or in normal individuals at the height of alimentary lipemia, moderate in patients with essential hypercholesterolemia, and minimal or absent in normal fasting subjects. Even in the presence of optimal substrate concentration, there may be individual variations in the clearing factor activity re- sulting from a given dose of heparin, and hence in the rate of fatty acid evolution. In addition, the rate at which the free fatty acids are removed from the circulating blood may be variable. Since there is competition between albumin and the lipoproteins for the available fatty acids, the relative concentrations of these proteins in the plasma will also be significant.

An important factor is the technique used in preparing the plasma sample for electrophoretic study. Most of the publications quoted above do not mention any precautions intended to halt in vitro fat hydrolysis after the blood was drawn, so that it must be presumed that the clearing reaction was allowed to proceed in vitro to a variable extent. In the experiments reported here, chilling to $0^{\circ}$ was employed as a means of limiting reaction in vitro. The cooling process is by no means instantaneous, however, and there is a remaining uncertainty regarding the actual extent of combination of fatty acid anions with lipoproteins in the circulating blood of the intact patient. It would appear, however, that with the presumably unphysiologic stimulus of heparin injection, fatty acids may be released in vivo at a rate temporarily exceeding the ability of the organism to remove them.

The mechanism of the oleate-lipoprotein interaction is not revealed by these experiments. Since the calculations of Oncley, Gurd, and Melin (26) indicate that a considerable portion of the surface of the beta lipoprotein molecule is composed of lipid material, it would not seem unreasonable to suppose that oleate ion, with its high surface activity, would tend to form a monomolecular film at the resulting lipid-water interface. The same conditions might prevail with alpha lipoprotein, although in this case there is no available evidence to indicate a superficial location of the lipid moiety. If surface activity is in truth the major factor in determining the association of oleate with lipoproteins, it is to be expected that other anionic surface active agents will behave similarly and produce equivalent electrophoretic changes. A preliminary survey of several natural and synthetic surface active anions, not of the fatty acid series, has indicated that this is, in fact, the case.

Earlier authors have observed alterations in the mobility of beta globulin components under 
experimental conditions differing from those employed in this study. Pure beta lipoprotein shows notable variability in its electrophoretic mobility, with the mobility tending to increase with ageing (29). Moore, Roberts, Costello, and Schonberger (30) have reviewed earlier experience, and describe experiments which demonstrate a tendency for beta globulin to migrate with the alpha globulins in plasma samples subjected to considerable handling or to long storage without refrigeration. Herbst and Hurley (17) also noted that lipemic plasma samples kept three to four weeks in the refrigerator showed electrophoretic changes similar to those observed in post-heparin specimens. In the present study, all samples were kept in the cold and analyzed promptly without excessively prolonged dialysis, so that such artifacts may be ruled out as causes for the observed effects. Addition of large amounts of heparin to plasma in vitro may also produce electrophoretic changes that have a superficial resemblance to those reported here. Chargaff, Ziff, and Moore (31) found that heparin added in vitro at a concentration of $4 \mathrm{mg}$. per $\mathrm{ml}$. could abolish the beta anomaly and produce a pre-albumin component in normal plasma. This fast component was also seen when heparin was added to a partially purified albumin fraction. Subsequent authors have observed similar effects; these experiments are reviewed by Nikkilä (11). In each case the concentrations of heparin required to produce electrophoretic changes by direct action in vitro exceeded by one hundred-fold or more the quantities that suffice to produce changes when injected in vivo in the presence of lipemia. In view of the demonstration by Lever, Smith, Hurley, and Herbst $(13,17)$ that heparin in vivo has no effect in the absence of lipemia, and its lack of effect when added in vitro at low levels, it must be concluded that heparin as such is not producing the phenomena under discussion here.

In addition, it should be noted that Macheboeuf and Tayeau (32) showed an effect of oleate on plasma lipids, rendering them extractable by ether in the cold. Presumably oleate ruptured the lipidprotein bond. This effect was observed only at concentrations of oleate significantly higher than those employed in this study.

The tendency of lipoproteins to bind oleate (and presumably other fatty acid anions) is of impor- tance in the interpretation of previous experimental work, and may serve as one fact which will eventually be of use in elucidating the detailed structure of these complex materials. At this time it seems doubtful that the interaction plays a significant role in physiologic fat metabolism, as the available data $(33,34)$ indicate that only trace amounts of free fatty acids occur in plasma, and that these small quantities are bound by albumin. The data of Figure 5 indicate that the existing quantity of fatty acid anion in plasma must be increased many fold before any oleatelipoprotein interaction occurs. The possibility that a different situation might exist in pathologic conditions remains to be investigated.

\section{SUM MARY}

Addition of sodium oleate to human plasma causes an increase in the mobility of alpha and beta lipoproteins, as well as the more familiar increase in the mobility of albumin. This effect is considered to be due to association of oleate ions with the lipoproteins, giving them a greater negative charge. In the case of beta lipoprotein, this association is shown to be reversible. This fatty acid-lipoprotein interaction is believed to be responsible for the electrophoretic changes which have been observed to occur after injection of heparin into lipemic animals or humans, inasmuch as such injection of heparin gives rise to a clearing factor known to be capable of effecting the hydrolysis of triglycerides with liberation of free fatty acids. The possible significance of the interaction is discussed.

\section{ACKNOWLEDGMENT}

The interest and suggestions of Dr. C. B. Anfinsen have been extremely valuable and are gratefully acknowledged by the author.

\section{REFERENCES}

1. Hahn, P. F., Abolishment of alimentary lipemia following injection of heparin. Science, 1943, 98, 19.

2. Anderson, N. G., and Fawcett, B., An antichylomicronemic substance produced by heparin injection. Proc. Soc. Exper. Biol. \& Med., 1950, 74, 768.

3. Shore, B., Nichols, A. V., and Freeman, N. K., Evidence for lipolytic action by human plasma obtained after intravenous administration of heparin. Proc. Soc. Exper. Biol. \& Med., 1953, 83, 216. 
4. Brown, R. K., Boyle, E., and Anfinsen, C. B., The enzymatic transformation of lipoproteins. J. Biol. Chem., 1953, 204, 423.

5. Gordon, R. S., Jr., Boyle, E., Brown, R. K., Cherkes, A., and Anfinsen, C. B., Role of serum albumin in lipemia clearing reaction. Proc. Soc. Exper. Biol. \& Med., 1953, 84, 168.

6. Korn, E. D., Properties of clearing factor obtained from rat heart acetone powder. Science, 1954, 120, 399.

7. Robinson, D. S., and French, J. E., The role of albumin in the interaction of chyle and plasma in the rat. Quart. J. Exper. Physiol., 1953, 38, 233.

8. Korn, E., Gordon, R., Anfinsen, C. B., Cherkes, A., and Quigley, T., Unpublished data.

9. Boyle, E., Bragdon, J. H., and Brown, R. K., Role of heparin in in vitro production of alpha lipoproteins in human plasma. Proc. Soc. Exper. Biol. \& Med., 1952, 81, 475.

10. Lindgren, F. T., Freeman, N. K., and Graham, D. N., In vitro lipoprotein transformations. Circulation, 1952, 6, 474.

11. Nikkilä, E., Studies on the lipid-protein relationships in normal and pathological sera and the effect of heparin on serum lipoproteins. Scandinav. J. Clin. \& Lab. Invest., 1953, 5, Supp. 8.

12. Lever, W. F., Smith, P. A. J., and Hurley, N. A., Effects of intravenous heparin on the plasma lipoproteins in primary hypercholesteremic xanthomatosis and idiopathic hyperlipemia. Science, 1953, 118, 653.

13. Lever, W. F., Smith, P. A. J., and Hurley, N. A., Idiopathic hyperlipemia and primary hypercholesteremic xanthomatosis. III. Effects of intravenously administered heparin on the plasma proteins and lipids. J. Invest. Dermat., 1954, 22, 71.

14. Nikkilä, E. A., The effect of heparin on serum lipoproteins. Scandinav. J. Clin. \& Lab. Invest., 1952, 4, 369.

15. Rosenberg, I. N., Serum lipids studied by electrophoresis on paper. Proc. Soc. Exper. Biol. \& Med., 1952, 80, 751.

16. Comfort, A., The effect of $\beta$-lipoprotein concentration on the action of injected heparin in the rabbit. Biochem. J., 1954, 56, IX.

17. Herbst, F. S. M., and Hurley, N. A., Effects of heparin on alimentary hyperlipemia. An electrophoretic study. J. Clin. Invest., 1954, 33, 907.

18. Bolinger, R. E., Grady, H. J., and Slinker, B. J., The effect of injected heparin on the electrophoresis of the lipoproteins in patients with hypercholesterolemia. Am. J. M. Sc., 1954, 227, 193.

19. Armstrong, S. H., Jr., Budka, M. J. E., and Morrison, K. C., Preparation and properties of serum and plasma proteins. XI. Quantitative interpretation of electrophoretic schlieren diagrams of normal human plasma proteins. J. Am. Chem. Soc., 1947, 69, 416.
20. Anfinsen, C. B., Boyle, E., and Brown, R. K., The role of heparin in lipoprotein metabolism. Science, 1952, 115, 583.

21. Swahn, B., Studies on blood lipids. Scandinav. J. Clin. \& Lab. Invest., 1953, 5, Supp. 9.

22. Markham, R., A steam distillation apparatus suitable for micro-Kjeldahl analysis. Biochem. J., 1942, $36,790$.

23. Sperry, W. M., and Webb, M., A revision of the Schoenheimer-Sperry method for cholesterol determination. J. Biol. Chem., 1950, 187, 97.

24. Fiske, C. H., and SubbaRow, Y., The colorimetric determination of phosphorus. J. Biol. Chem., 1925, 66, 375.

25. Bragdon, J. H., Colorimetric determination of blood lipides. J. Biol. Chem., 1951, 190, 513.

26. Oncley, J. L., Gurd, F. R. N., and Melin, M., Preparation and properties of serum and plasma proteins. XXV. Composition and properties of human serum $\beta$-lipoprotein. J. Am. Chem. Soc., 1950, $72,458$.

27. Klotz, I. M., and Ayers, J., Protein interactions with organic molecules. Disc. Faraday Soc., 1953, 13, 189.

28. Cogin, G. E., The effect of elaidic acid on the electrophoretic behavior of bovine serum albumin. Abstracts of Papers 119th Meeting, Am. Chem. Soc., April 1951, p. 28C.

29. Oncley, J. L., and Gurd, F. R. N., The lipoproteins of human plasma, in Blood Cells and Plasma Proteins, Their State in Nature, edited by J. L. Tullis, New York, Academic Press, Inc., 1953, p. 337.

30. Moore, D. H., Roberts, J. B., Costello, M., and Schonberger, T. W., Factors influencing the electrophoretic analysis of human serum. J. Biol. Chem., 1949, 180, 1147.

31. Chargaff, E., Ziff, M., and Moore, D. H., Studies on the chemistry of blood coagulation. XII. An electrophoretic study of the effect of anticoagulants on human plasma proteins, with remarks on the separation of the heparin complement. J. Biol. Chem., 1941, 139, 383.

32. Macheboeuf, M., and Tayeau, F., Sur l'etat des lipides et du cholestérol dans le sérum sanguin; destruction de certaines cénapses lipidoprotéidiques et libération de leurs substances lipoidiques par un savon. Compt. rend. Acad. d. sc., 1938, 206, 860.

33. Cohn, E. J., Hughes, W. L., Jr., and Weare, J. H., Preparation and properties of serum and plasma proteins. XIII. Crystallization of serum albumins from ethanol-water mixtures. J. Am. Chem. Soc., 1947, 69, 1753.

34. Davis, B. D., The estimation of small amounts of fatty acid in the presence of polyoxyethylene sorbitan partial fatty acid esters ("Tween") and of serum proteins. Arch. Biochem., 1947, 15, 351. 